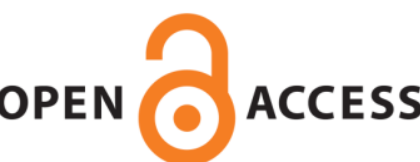

UWS Academic Portal

\title{
Why do women attend writing retreats?
}

Murray, Rowena; Kempenaar, Larissa

Published in:

Gender and Education

DOI:

10.1080/09540253.2018.1557321

Published: 12/01/2019

Document Version

Peer reviewed version

Link to publication on the UWS Academic Portal

Citation for published version (APA):

Murray, R., \& Kempenaar, L. (2019). Why do women attend writing retreats? Gender and Education, 32(8), 1001-1018. https://doi.org/10.1080/09540253.2018.1557321

\section{General rights}

Copyright and moral rights for the publications made accessible in the UWS Academic Portal are retained by the authors and/or other copyright owners and it is a condition of accessing publications that users recognise and abide by the legal requirements associated with these rights.

Take down policy

If you believe that this document breaches copyright please contact pure@uws.ac.uk providing details, and we will remove access to the work immediately and investigate your claim. 
"This is an Accepted Manuscript of an article published by Taylor \& Francis Group in Gender and Education on 12/01/2019, available online: http://

www.tandfonline.com/10.1080/09540253.2018.1557321". 


\title{
Why do women attend writing retreats?
}

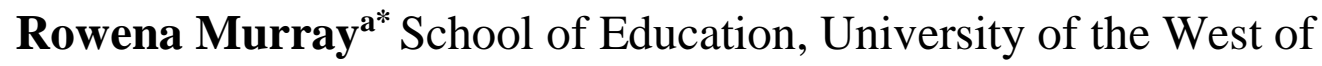 \\ Scotland, UK, ORCID 0000-0002-3209-9290 \\ Email: Rowena.murray@uws.ac.uk
}

\begin{abstract}
Larissa Kempenaar ${ }^{\mathbf{b}}$ School of Health and Life Sciences, Glasgow Caledonian University, Scotland, UK, ORCID 0000-0002-6259-2035 Email: l.kempenaar@gcu.ac.uk
\end{abstract}

Address for correspondence: *Rowena Murray, School of Education, University of the West of Scotland, University Avenue, Ayr, KA8 0SX. Phone: 07868742534.

\section{Author biographies}

Rowena Murray graduated with MA (Hons) from Glasgow University and PhD from Pennsylvania State University. She is Professor in Education in the School of Education at the University of the West of Scotland and Principal Fellow of the UK Advance Higher Education. Her teaching and research focus on academic writing, the subject of her many books and journal articles. Her research has been funded by the British Academy, the Carnegie Trust and the Nuffield Foundation.

Larissa Kempenaar has been a lecturer in Physiotherapy in the School of Health and Life Sciences at Glasgow Caledonian University since 2002. She is the Deputy Programme Lead for the MSc in Physiotherapy and the newly accredited Doctor in Physiotherapy programme. Her research interests include understanding academics' writing behaviour and the role of Structured Writing Retreats. Her educational interests include community-university partnerships and doctorateness as a threshold concept 


\title{
Why do women attend writing retreats?
}

\begin{abstract}
Inequality in academic careers is structural and systemic. However, the growing writing retreat movement offers alternative structures for academic work, and in many countries retreats are mostly attended by women. We asked women about their experiences of retreats and did a systems and transactional analysis of their appraisals of writing and perceptions of relationships with systems at work. This article provides some answers to the question of why writing retreats are attractive to and seem to benefit women. A Structured Writing Retreat is one place where women can develop process, performance, prospect and profit beliefs in relation to their writing by creating a microsystem that sustains those beliefs. However, ambivalence in responses - in relation to research assessment, management and teaching overload - is a reminder of the overarching systems in which they work. This research shows that some women can counter some discriminatory practices, some of the time, at writing retreats.
\end{abstract}

Keywords: writing retreats, gender, career progression

Total word count: 8,970, 36 pages 


\section{Background}

Inequality in academic careers has been thoroughly evidenced (David 2015, HEFCE 2011, HESA 2017a \& b). Although approximately 50\% of academics are women, far fewer are in professorial and senior management positions. For example, in the United Kingdom (UK), 24\% of professors and 34\% of senior management are women (HESA 2017a \& b), and the mean gender pay gap is 18-20\% (Equality Challenge Unit 2017). These inequalities are paralleled in statistics for Higher Education (HE) in Australia, USA and Europe. There is evidence of inequality in promotions, publications and HE cultures across the world (Gatrell et al. 2017, Gill 2009, HESA 2017a \& b, Larivière et al. 2011, Savigny 2014). This is a waste to both the economy and knowledge construction (Morley 2013).

Women academics may experience harassment (Valentine 1998), chronic or episodic ‘micro-inequities’ (Aiston 2015a), ‘cultural sexism’ (Savigny 2014) and ‘subtle gender biases’ (Nielsen 2016, 386). Their publications are likely to have lower ratings than men's, they receive lower levels of research funding and have lower research productivity than men (Larivière et al. 2011), and a recent study of more than a thousand academics on five continents showed that pressure to publish can have 'personal costs, in the form of health concerns and work-family conflict ... more so for women than for men’ (Richard et al. 2015).

Initiatives to address gender inequality include training, networks of women leaders, longitudinal research on women's careers and institutional awards to recognise equality work. However, discriminatory practices continue to be 'structural and systemic' (Aiston 2015b: 205).

Theoretically, inequality in research outputs can be turned around through writing 
retreats (Moore et al. 2010, Murray 2012, 2013, 2014, 2015, MacLeod et al. 2012, Sonnad 2011), and far more women attend writing retreats than men: a ratio of at least 75:25 and often as high as 90:10 in countries where retreats are run. While there is a significant body of research on writing retreats, there is a distinct gap: why do more women than men attend, and do they benefit more from retreats? One study has shown that writing retreats seem to benefit women more (Moore et al. 2010), and retreats should, theoretically, improve women’s career progression. However, increasing publications does not produce equality (Littler 2013, Nielsen 2016, Savigny 2014). Our observations suggest that writing retreats do more than boost productivity, but we need to know more about women's experiences of writing retreats. This might help us to understand why more women than men attend and if there is a role for retreats in tackling inequality.

As a first step, we conducted an exploratory pilot study. Findings from a focus group suggested that increasing research output was a 'given' for those attending writing retreats, but ambiguity was expressed in terms of the 'moving goal posts' of academia. The aim of this article is to explore women's perceptions of their experiences of writing retreats. As far as we are aware this is the first gendered account of women's experiences of writing retreats.

\section{Methods}

\section{Recruitment}

A database was created of women who had attended Structured Writing Retreats run by the first author between 2005 and 2015. These residential retreats consisted of 10.5 hours of writing over three days in a hotel in a rural setting, with between ten and twenty participants. They followed the format of Structured Writing Retreats (SWR) 
(Murray and Newton 2009), with a fixed programme of writing time slots and breaks. Services and amenities on site included meals and snacks, walks and a bar. The first author organised the venue and facilitated these retreats: introducing the SWR approach, explaining the use of goal-setting for writing and the value of 'unplugging' from email and internet in order to concentrate exclusively on writing, holding participants to the fixed time slots and supporting individual writers, if required.

Records of retreats in this period were transferred to the researcher (second author) and entered in an Excel spreadsheet. Missing data, in terms of place of work and email address, were traced through an internet search. Full details for participants from the period 2012-2015 were already held on record by the researcher. The inclusion criteria were that participants (a) were female and (b) had participated in at least two writing retreats during the 10-year period. The second criterion was based on our observation that repeat attendance at retreats suggested buy-in to the model, and it meant that participants had more experience of this model of retreat. Furthermore, feedback and evaluations over this ten-year period had suggested that the impact of writing retreats was more ambiguous for those attending only once, an observation confirmed by Moore et al. (2010). An email was sent to participants who met the inclusion criteria, with an information sheet attached. Ethical approval was obtained from the School of Education at the University of the West of Scotland. The information sheet and consent form explained the purpose of the study and outlined the need for participants to be computer-literate and willing to use synchronous online chat.

Over the ten-year period, 308 people took up 679 places at 70 writing retreats. The number of times they attended ranged from one to 24, with an average attendance of 2.2 retreats. Of the 308, 231 (75\%) were female. Thirty-three had attended two or more writing retreats during this period. Contact details were unavailable for three 
participants, leaving 30 (10\%) who were invited to participate in this study. Seven agreed to take part. After several attempts, a mutually agreed time could not be found for one participant who declined to participate, resulting in six participants being interviewed between July 2016 and February 2017. One interview took place by email, one using Messenger, with the remaining interviews taking place on Skype chat. While all participants agreed to participate and use computer mediated communication, the speed and style of their interactions suggested that only one was experienced in using synchronous, online chat. Interviews lasted between 25 minutes and 2 hours.

All participants worked in academia at the time of the interview and had done since they first attended writing retreats. They held a range of positions in their institutions. Most were in first-level posts (Lecturer or Teaching Fellow) and had been working in HE for between one to $10+$ years. Two had completed doctorates in the previous two years and had since gained employment in HE. Five worked in UK universities and one in a European university.

\section{Data Collection}

Interviews were conducted by a researcher who had not facilitated retreats attended by participants, using computer mediated communication (CMC), which was selected for two reasons: firstly, to enable participants from across the UK and Europe to take part; and secondly, the budget was limited, which meant it was not possible for the researcher to travel to participants. Synchronous chat software (Messenger and Skype), freely available to participants, was used to conduct and capture the interviews. Participants were asked to choose the online chat medium they preferred. The following questions were used in interviews. 


\section{Interview Schedule}

\section{Introductory Questions}

1. Can you tell me a bit about yourself?

Follow up:

- What kind of work do you do within the University?

- What is your position? (permanent, part time, lecturer, etc.)

- What was your doctoral degree about?

\section{Key Questions}

2. Can you tell me something about your experiences of writing retreats?

Follow up:

- What have been the main benefits of writing retreats?

- Can you tell me more about that?

3. Do you think writing retreats have played a role in terms of your academic position? If yes: Can you tell me a bit more about that?

\section{Closing question}

Is there anything else you would like to add?

Participants were offered the opportunity to ask questions prior to the interview in an email. The chat transcripts were copied and pasted into a MS Word Document. The original chat was deleted once the transcript had been exported.

\section{Data analysis}

Transcripts were analysed using a framework analysis adapted from Gale et al. (2013). This consisted of six stages: familiarisation, coding, developing the analytical framework, applying the framework, charting the data and finally interpreting the data. For familiarisation, the researcher read through all interview transcripts and wrote reflective comments in the margins. This was followed by coding the transcripts line- 
by-line. Comments were noted in the margin on interpretations of meaning, substantive issues, values, emotions, impressions or methods.

\section{Theoretical framework}

The theoretical framework was based on the transactional and systems approach we developed for analysing the complexity of academic writing (Kempenaar and Murray 2016, 2017). Because we found it useful in understanding not only how individual writers navigate the systems that impact on their writing but also how they appraise their writing, offering insights into the powerful role played by writers' beliefs, we decided to use it in this study. This is the first time this approach has been used to analyse women academics’ experiences.

The transactional approach considers writing behaviours and practices in terms of the individual's appraisals of writing and her perception of relationships between the systems in which she is embedded. It is concerned with the individual's beliefs about behaviours (Kempenaar and Murray 2016). These beliefs are related to a person’s ability to perform (performance belief), to carry out a behaviour required (process belief) in order to achieve a certain goal (prospect belief). How this behaviour is perceived as benefitting the individual is termed profit belief.

It is perhaps useful to review the difference between belief and behaviour. Belief is defined here as those thoughts related to something which the individual deems to be the case, with or without empirical evidence to confirm it. For our analysis, when we discuss 'beliefs', these refer to participants' perceptions of behaviours, rather than actual behaviours. 
The limitation of the transactional approach is that it does not consider the environment or structure in which the individual is sited, which is why we also used a systems approach in our analysis (Bronfenbrenner 1977). This provides a model of relationships between the structures and the individual. These include the microsystem (the relationship between the individual and their immediate line management and colleagues), the mesosystem (the relationships between those in the microsystem), the exosystem (the organisation in which the microsystem is sited, in this case the university) and the macrosystem (the system in which the exosystem is situated, e.g. society, academe, culture).

Thus, we used a transactional approach to identify participants' perceptions, in order to answer the first research question - why are writing retreats attractive to women? - and a systems approach, to answer the second - why do writing retreats seem to benefit women?

For this analysis, both authors coded one interview and discussed the codes and suitability of the framework and agreed working definitions for each category. The researcher then read the transcripts again, applying the categories. Data were charted in a framework matrix, and we explored relationships and connections between categories.

\section{Results and Discussion}

\section{Beliefs about writing process and performance}

Data were analysed using the categories of the transactional and systems approach. 
While it is possible to isolate different beliefs and systems in participants' writing, they generally talked about different beliefs in the same sentences. For example, many participants not only discussed what they believed to be the processes required for writing but also expressed performance beliefs, i.e. their beliefs about their ability to perform these processes and achieve intended outcomes. However, in order to make sense of their experiences of writing retreats, it is useful to consider process and performance as separate beliefs.

For example, participants discussed a number of process beliefs in terms of the behaviours that they believed to be helping and hindering their writing. Process beliefs were considered positive if they concerned their beliefs about the behaviours required to cope with the situation. In other words, this meant behaviours related to writing perceived by these women as helpful in achieving their goals. Writing retreats were described as ' $a$ ' or 'the' place where they believed they could do what they needed to do to be effective in producing written output. They described behaviours engendered by, and at, writing retreats and their perceived effectiveness in producing research output. Furthermore, they described how these behaviours were structured and embedded in the retreats they attended, but also how they might be applied outside the retreat setting.

The behaviours they described reflect the main principles of writing retreats, including fixed writing slots, goal setting and the absence of other demands. Three women described the usefulness of the fixed writing slots and the importance of the length of each writing session. One woman, who was facilitating writing retreats herself, highlighted the importance of the duration of these writing slots: 'Long enough to get something done; not so long that people start leaving etc.' (Julie 157-158). Lauren 
added that a writing slot did not have to be at a specific time of day: it 'does not have to be the perfect moment for writing and you can just take one hour or another time slot to achieve something' (Lauren 78-80). Katherine described the planned, fixed writing time slots as 'mechanistic ... but keeping time for writing as I would for teaching is important' (Katherine 127-128). While the benefits of adhering to writing slots and prioritising writing over other academic duties are well known, there is a gendered account of these benefits for women in this study:

'it removes those related demands for the period of time while away (notwithstanding the prep time and time needed once returned) ... And while away, someone else does the shopping, cooking, cleaning, etc., which again frees up time and energy’ (Jane 171-175).

The importance of this prioritised and planned time for writing was also described by Sophie, who, although no longer attending retreats, described how she still used the practice of having planned time dedicated to writing: 'What I do now is every couple of months I block about a week in my diary and dedicate that to research writing’ (82-84). She identified the temporal nature of process beliefs, as she 'found writing retreats great for me at that time in my career. I probably don't need them now but they taught me a lot at that time and I draw on that learning now to help with my writing' (Sophie 86-88). Although she no longer attended retreats, she identified specific processes that she believed to be helpful.

Participants discussed their performance beliefs in relation to specific processes. Performance beliefs refer here to beliefs regarding the ability to perform a process. For example, while the time slots were found to be useful, Jane and Katherine stressed that 
it was important to use this writing practice regularly. While Katherine discussed her experience of the effectiveness of this, Jane said she struggled to implement this herself. This suggests that while her process beliefs were strong, in terms of regularity of writing, her performance belief was weak, as she felt that she struggled to do this.

Another example of this contrast in beliefs is illustrated by Sophie: 'Yes, I have learnt a lot from these retreats and when I block off time for writing I try to mimic the same approach' (59-61). Her use of 'try' suggests that while she identified the usefulness of blocking out time, she seemed ambivalent in her belief about her ability to perform this behaviour to achieve her goals.

In contrast, many participants described processes that made it difficult for them to write, i.e. negative process beliefs: 'The issue sometimes isn't the writing or the research but the absence of strategies to keep the teaching and admin contained' (Dawn 40-42). This suggests that behaviours to support writing are not limited to positive process beliefs about writing. Dawn had described earlier that she had positive process beliefs about writing retreats, as they provided her with protected research time. While she had positive process beliefs about writing retreats, this was off-set by negative process beliefs in terms of a lack of strategies in her work setting and her inability to protect research time. In addition, she appears to have weak performance beliefs regarding her ability to manage time: 'Logically, research time is where you make up the difference - or personal time. Our university works to a 40/40/20 split for teaching, research and administration, so depending on your admin responsibilities you might be able to claw back some time there' (Dawn 26-28). 
While evidence from other studies suggest that the principles of writing retreats can be transferred to other settings, this study suggests that this is not always the case: weak performance beliefs are a way of explaining this, and writing retreats are a way of addressing this.

Our analysis did not always reveal divergence between process and performance beliefs. Katherine and Lauren described how goal setting and reviewing goals were useful: 'I started being able to judge what could be done with what timescale and set a goal for that time' (Lauren 77). This suggests a strength in process beliefs, while at the same time enhanced performance beliefs. This could be interpreted as a sign that, for some women, writing retreats could facilitate convergence between performance and process beliefs. This convergence was also observed in Lauren's narrative, when she described how she developed her performance beliefs at retreats: 'So I have been to about 10 writing retreats in total I think and found the experience invaluable. This is because they taught me how to structure my thoughts and ideas onto the page and how to be pragmatic and structured in writing for a purpose' (Lauren 63-65). She is clearly aware of the process required, and her experience of retreats enabled her to develop strong performance beliefs: 'Academic writing was something I was struggling with but [xxx]'s book and the retreats really helped me to develop that skill. By reading, reflecting and participating' (Lauren 86-89).

The role of writing retreats in developing performance beliefs was also suggested by Julie: 'the idea that everyone has fears, but write and submit anyway. That was a big thing. Of course, the idea that you CAN get writing done if you just get on with it' (Julie 232-234). This was confirmed by Dawn: 'I was anxious about the first one (not 
knowing what to expect) but then with each subsequent one I was less anxious about the process (but often still quite anxious about the writing task I had set myself)' (48-50).

Sophie, the only participant in this study who held a senior managerial position, was also the only participant who said she no longer felt the need to attend writing retreats, and she also expressed very strong process and performance beliefs, in terms of the need to plan dedicated writing time: 'If I want to engage in research writing I now need to ensure I find time in my diary to do so.... What I do now is every couple of months I block about a week in my diary and dedicate that to research writing’ (Sophie 76-83). However, like others in this study, she expressed ambiguity in her performance belief when she said her ability to perform this behaviour was limited by the challenge of managing competing demands: 'I find it difficult to make time given the leadership roles which I now have’ (Sophie 44-46).

Participants in this study also expressed performance beliefs in terms of their inability to perform, practices they perceived as effective: 'I am still working on “parking” work. I have to work hard to stop thinking about work/writing when I am doing other things' (Katherine 130-131), where the word 'still' suggests that her efforts to achieve her goals were not always successful.

\section{Prospect beliefs}

Prospect beliefs are defined as beliefs about likely outcomes. In the context of writing, we looked for statements about the output and outcomes of writing practices. All participants acknowledged the importance of producing research outputs: 'Writing for publication and research proposals is very important for any research active academic' (Sophie 69-70). For some participants, prospect beliefs were related directly to the 
outcomes of attending retreats as part of their writing practice, while others discussed the outcomes related to writing practices generally. For example, both Jane and Sophie identified that the requirements of the job meant that they would have published anyway, using writing practices in other settings, but that retreats facilitated an increase in their productivity. Jane said that retreats improved the quality of her writing.

Sophie put the importance of writing in the context of her other managerial roles. This would explain why Sophie, in contrast with the other participants, indicated that she did not need to use retreats for her writing: 'They are still important but other things are also now important including how I deliver on expectations concerning my leadership of the [organisation] and also Faculty responsibilities’ (72-74).

Some participants discussed their experiences in relation to the United Kingdom's performance-based funding systems for universities, the Research Excellence Framework (REF), which runs in 4- or 5-year cycles. The aim of the REF is 'to inform the selective allocation of funding for research' and to produce 'benchmarking' and ‘reputational yardsticks' (ref.ac.uk, consulted 15.11.18). Journals in each discipline will have a 'star' rating, and each individual academic's publications will be rated in this way. Institutions prepare for REF through various forms of 'mock REF'. Institutions that score highly in the REF will attract significant government funding for research; institutions with low REF scores will have little or no funding for research. Individuals who are not submitted for REF - not 'REF-able' - are considered not to be 'research active', which means that research is not part of their workload, i.e. not part of their job. Whether a person is 'REF-able' will be considered by promotions panels and will impact on career progression. The REF therefore has a significant effect on academic 
writing, including considerations of where to publish. Ironically, individual academics may have publication targets but little or no dedicated writing time as part of their defined workload. REF has therefore arguably made academic writing more difficult and more competitive. In this performative context, writing retreats were developed to create a productive, collaborative space for writing.

Jane's prospect belief in terms of her ability to produce 'REF-able' output was very positive: 'Yes, I've been doing alright. I scored well in the lead up to the last REF, though our department had fewer three-stars than anticipated by the internal and external assessments leading up to our submission’ (114-118).

Participants discussed other outcomes, other than research outputs, such as Katherine who expressed ambiguity in her prospect belief when asked how effective she was at dealing with the stresses of writing and rejection: 'Ask me again next year :-) It certainly helped with writing a chapter for my colleague’ (133-138). This illustrates ambiguity regarding long-term outcomes, while her belief in the short-term outcome was more positive. Participants also discussed their beliefs about outcomes of writing retreats in relation to social support, which we discuss later, when we used the systems approach, under the heading of micro and mesosystem.

Interestingly, participants also expressed a form of vicarious prospect beliefs: 'Repeat attendance [at retreats] also allowed me to see how people developed at different stages of writing a thesis and gave me a sense that I was progressing too’ (Katherine 102-104). 


\section{Profit belief}

Profit beliefs are defined as beliefs about how outcomes are likely to impact one’s interests and aims. In the context of writing, profit beliefs are representations of how much the individual believes she will profit (or lose) from publishing research or completing a thesis, and how an outcome advances her life goals. Three processes at retreats seem to be central to profit control: setting goals, controlling tension and adapting interests and aims to obtain outcomes, and all three were part of these women's experiences of writing retreats.

Profit beliefs were discussed by participants in relation to their current career attainment. Lauren, Jane and Dawn talked about the outcomes they achieved and how these related to writing retreats, in close association with the profit belief regarding the benefit they had in terms of their current positions. For example, Lauren said, 'Without the retreats I am pretty sure I could not have written a thesis. And everything has come about as a result of that' (92-93). Jane articulated the relationship between the outcome of writing in relation to being included in the REF. For Jane, being included in the REF (prospect belief) was directly related to her chance of career progression (profit belief):

'Being included in the REF is one of the single-most important criteria that research-active faculty are judged against. Not being included in the REF, especially more than once, would probably mean the end of any chance of promotion and would likely mean pressure to be put on a teaching only contract' (Jane 107-110).

The issue of the REF in relation to output was also reflected in Dawn's statement: 'Yes the REF 2020 makes research public but that is in the future and its leverage is based on 
publications I do not yet have’ (Dawn 33-34). This is ambiguous, as she acknowledged the importance of the REF as a strong profit belief but suggested limited impact by using the word 'probably'.

However, participants expressed other kinds of profit associated with the outcomes of their writing: 'Other than the personal satisfaction of having got some research out there :-)’ (Julie 107-108). This conveys her sense of the absence of reward in terms of her academic status, but the benefit of personal satisfaction, which acted as a motivator to continue writing and publishing. She discussed publishing as achieving a sense of satisfaction that was not directly related to the aims of her work but identified potential profit she might obtain: 'and it MIGHT give me a bit of leverage when I ask for a study leave... (she says with her fingers crossed)' (110-111). This profit is small ('a bit'), the belief ambiguous ('might' in capitals), and it may be determined by luck ('fingers crossed'). This suggests that her positive profit beliefs, in terms of personal satisfaction, and ambiguous profit belief regarding work profit, were sufficient to motivate her to continue publishing.

Ambiguity in relation to profit was also expressed by Dawn: 'My claim to leadership through academic writing will be worth diddly-squat [nothing] if the content of my publications is in doubt' (142-143). This illustrates that while someone might have strong performance, process and prospect beliefs, profit in terms of career progression might remain out of reach. Dawn and Julie also suggest that profit beliefs act as an important motivator to continue their efforts in academic writing. Further experience could increase or decrease the ambiguity in their profit beliefs and will likely influence their motivation to write for publication. 
Sophie was the only participant who assigned writing a smaller part in her career progression to her current managerial positions: 'I think it would not be appropriate to say there is a direct link between writing retreats and my current position - I have worked really hard across all elements of my job and of course writing is only one of them’ (Sophie 65-67).

In contrast, Katherine discussed personal losses she had experienced as a result of writing outcomes in terms of her health and wellbeing: 'the deterioration in my health was most probably related to the stress of paper writing' (115-116). This belief was associated with her performance belief regarding her ability to produce peer reviewed journal articles and sufficiently, negatively strong for her to stop writing for publication:

'I find the process of writing very stressful. I am being literal when I say that after the two papers I tried to write (one accepted for publication and one not) I ended up in hospital on both occasions and quite frankly that is very strong aversion therapy for the process of academic writing - although I find other types of academic writing easier, e.g. book chapters or non-peer reviewed articles for a teacher’s journal' (36-41).

While Katherine had sufficient process, performance and prospect beliefs to write for academic publication, this came at a price, and her profit belief was weakened by her experience, to the extent that she no longer wanted to write for peer reviewed journals and she opted for a contract that did not require her to do so. Developing all of these forms of belief may be important for some women to keep 
writing: 'The structured retreat is one strategy amongst many but it has been key in developing my inner cheerleader’' (Dawn 52-53, 59-63).

The transactional approach we used for this analysis considered these women's writing behaviours and practices in terms of their appraisals of their writing, both during and after retreats. By focusing on beliefs about behaviours we shed light on their beliefs about their writing ability, about their capacity to produce writing, about their writing goals and about benefits that publishing brings.

\section{Microsystem}

The microsystem refers to individuals and groups that most directly impact on the person. In this study, these were described in interviews in relation to the immediate context in which the academic operated, namely the academic context, colleagues and immediate line management in their departments/faculties, but also people encountered at Structured Writing Retreats. Some of the women also discussed their home environments. In the interviews, unsupportive microsystems at work were frequently contrasted with supportive microsystems at retreats.

\section{The microsystem at the workplace}

The immediate environment of many participants did not appear conducive to writing in most instances: 'The hard part of the first paper was the emotional investment - and lack of support from my supervisor - but that was par for the course unfortunately’ (Katherine 68-69).

The microsystem in the shape of immediate line management was viewed by many as the enforcer of the university's ambitions and drivers. This was generally discussed in 
terms of a discrepancy between the intended purpose of regulations and policies and the execution of these, leading to pressures to perform while the women felt unsupported by their line managers. This discrepancy led in some instances to conflicting expectations: 'Most of my time is spent working with [postgraduate] students and I'm trying to develop writing - which is part of what I am expected to do despite it not being part of my contract’ (Katherine 12-14).

Katherine illustrates how she attempts to conform to expectations of a line manager, while acknowledging that this should not be required according to her contract (exosystem). She went on to provide another example of the discrepancy between intention and execution: 'But I was very annoyed at the way the process was handled as reviewers were told that they had to move people [to another department or REF Unit of Assessment] which is not what the review process is supposed to be about' (Katherine $18-20)$.

While many of the women discussed immediate line management, Jane discussed the influence of colleagues and how this impacted on managing roles:

'Women tend to approach their academic responsibilities more relationally, and I think there is even an implicit (often unconscious) assumption that women should attend to the affective/emotional requirements of the job (e.g. a distressed student) more quickly or more competently than men - again, this is a generality and I think that a lot of men would disagree with this.... or that dimension of things remains invisible or, worse yet, is not deemed a valid use of our time.... 
And tending relationships and responding to the affective/emotional dimension of the job requires time and energy' (Jane 152-159).

Both negative and positive aspects of colleagues were discussed in terms of being a source of support or not. For example, Jane discussed how she purposefully aimed to create a positive environment, both at the retreat and at work: 'I try to collaborate with people who energise and/or inspire me' (Jane 52-53). The creation of supportive writing groups provided a positive microsystem, but as this in some cases was related to performance, there was ambivalence about this support: 'I was part of a publishing support group during the time of the second paper. Interestingly I was removed from this group without discussion by my [Annual Review] reviewer who led the group because I clearly wasn't going to be REF-able. And frankly that still p*sses me off' (Katherine 77-79).

The removal of support clearly led to distress. This suggests that a supportive microsystem is related to performance. Only one participant, already in a senior position within her university, suggested that she did not need a supportive system to do her writing. When asked what writing support she received she said, 'I am not sure what you mean by support? If I want to engage in research writing I now need to ensure I find time in my diary to do so' (Sophie 76-77). This suggests that not all academics require support in order to write. For Sophie, it could relate to her management post, or to a preference for solitary writing.

The microsystem at retreats

The experience of a supportive environment at retreat was described by Dawn: 
'This success is not achieved without the support of others. It seemed to me to be like cheerleading at a swim meet - everyone has their personal bests that they are trying to improve upon but integrated with that is the support for others, for the team medleys. I might be taking the metaphor a bit far but I decided during the $\mathrm{PhD}$ that I had a responsibility to believe in myself at least as much as others in the retreat did - I deliberately cheerleader myself' (Dawn 61-66).

This sport metaphor implies competition, but Dawn's description suggests the opposite. She describes the team effort to achieve individual goals. This appears to work in two ways. Firstly, the individual feels cheered on by others, and, secondly, there is a sense of responsibility to the group to continue this and for her to take responsibility for her beliefs in the context of this support fostered at the retreats.

Dawn explained how retreats provide a positive model in leading and supporting colleagues: 'the retreats are a particular pedagogy and knowing that is a very powerful leadership dynamic through which to support others’ (Dawn 147-149). Support in one workplace was moving in another direction: 'Going to [these] writing retreats was a formative experience for me. But now formal support is for people who are already producing papers, not for people trying to develop these skills’ (Katherine 90-92).

The microsystem of writing retreats also seems to relate to the experience of being cared for, where accommodation and full board are provided at a hotel, and in positive relationships with hotel staff and owners: 'not to mention the experience of being appropriately cared for while doing the intellectual labour of writing' (Jane 177-8). This 
aspect of writing retreat means that more energy and concentration can be dedicated to writing.

\section{The microsystem at home}

Katharine and Jane described how they were supported by partners at home: 'My husband is very supportive and would notice if I was getting too stressed and I would pull back from the writing' (Katherine 117-118). Katherine’s husband provided a microsystem that was lacking at work, where the microsystem pressurised her to publish, which had had a detrimental impact on her.

\section{Mesosystem}

The mesosystem refers to relationships and interactions between and within microsystems. Relationships between people were discussed by several participants. For example, Jane, following her description of the relational aspects of academic work, such as providing pastoral support to students, costing effort and energy, provided a balance to this aspect of work: 'That said, the relational aspects of the job can indeed be energising, so I don't want to be too simplistic about this’ (Jane 165-166).

Social support during the retreats was identified as a practice. It was discussed by Sophie during the agreeing of objectives and reporting back after writing. Dawn said that role modelling was an important part of the social process, and Julie said she 'loved the feeling of sitting in a room with a bunch of people writing, the dinner conversations were great. I still have friends that I met on that first retreat' (Julie 198-200). This process was not possible at work: ‘With the other demands of the job, it doesn’t feel possible to have a routine' (Jane 74 ). 
Dawn went beyond the relationships between people in her discussion of relationships between people and objects, as well as the relationship between objects:

'I am intrigued by the combination of technology (the wires, plugs, lights) the deliberate (necessary?) arrangement of tables in a circle and the sounds/smells and tastes of the food; the fact that everyone has to get down on their knees to "wire themselves in" and then everyone (not just the retreaters) has to agree to the terms of the retreat in order that it works. If any one of these things changes then the various social practices that keep the retreat in place change also - the retreat becomes something different. The retreat, as a practice, is constantly in flux (but seems on the outside perhaps to be quite stable and fixed)'.

This is perhaps a direction for future socio-material research on women's experiences of writing retreats.

\section{Exosystem}

The exosystem refers to relationships between the individual's immediate context and the social setting in which the individual does not have an 'active role'. In academia, this refers to the university as employer, how it operates towards its employees, how this influences academics' line management and how policy and regulations are implemented with employees. The 'university' refers here to management structures above immediate line management. We appreciate that this includes a range of management, from Heads of Department to the university executive. The number of levels of management above the participant also depends on the participant's position in her university. For example, one 
participant was very senior, with fewer layers of management above her, compared to the participant who was on her first contract as a lecturer.

The exosystem was discussed by many participants in terms of the Research Excellence Framework (REF) used in the UK, and how their universities' interpretations of REF criteria determined performance review of publications and research. The pressure to perform in REF was described in three ways: firstly, the pressure to publish described by Katherine above; secondly, the minimal quality of publications required, described by Jane and Julie and, thirdly, in terms of how people were 'managed': 'It really feels like it is publish or you are not worth a damn as far as the management of the School are concerned and that is NO WAY to treat people' (Katherine 80-81). The pressure to perform associated with REF was passed onto staff: 'Our new head of department and the internal REF panel are taking what appears to be an even more conservative approach to the assessment of publications, with lower scores than some of us might have anticipated’ (Jane 120-122).

The implications of not being included in REF were discussed by participants. Not being included in the REF limits career progression, and may mean 'demotion' to a teaching-only contract. This suggests that universities are perceived as giving teaching less value and/or status than research. It also means the identity and responsibilities of the academic are altered by removing research from her contract and roles. This happened to one participant who had struggled to produce sufficient publications: 'I am currently a Teaching Fellow in Education having been moved from an academic contract at our annual review process last year’ (Katherine 11-12). 
Research output was the criterion by which performance of the academic's contract was judged: 'But it is really annoying that on a teaching contract, to get time for "research and other scholarly activity” you have to show that you will produce a paper' (Katherine 95-96). The impact of this for most participants was, 'it places pressure on us to deliver, in terms of grants and REF submissions' (Jane 28-29). Julie, for example, discussed the discrepancy between her research and publication priorities and those of the university. The implication was that she did unpaid research. This had the advantage that the university did not scrutinize her work: 'If I was actually getting paid for research, I'd have to publish in journals that the university deems worthy, and some of those don’t really interest me' (Julie 74-75). Julie described not being part of the performance rating as freeing. She did research she wanted to do:

'I really like research. Finding stuff out. And I like the freedom to not have to worry about whether or not my research counts. So my position rather suits me. Though I do wish I had more time for research (which is why I'm plotting to go half-time next year)' (Julie 110-115).

\section{Macrosystem}

Macrosystem describes the culture in which individuals are embedded. This is the level over which individuals have least control. The culture most discussed by participants was the REF, as this determines universities’ priorities and strategies regarding research and research output: 'What I hate about formal academic writing is the pressure to perform. I can make a space for myself with less formal academic writing, which might have an impact but isn’t valued in the academy’ (Katherine 86-88). Katherine identifies that the culture of 'the academy' is such that only a certain standard of writing is valued, pointing out the discrepancy between impact and value. 


\section{The interplay of transactional and systems approaches}

The interplay between the transactional and systems approaches is about the components of behavioural beliefs, and how the systems of the individual, including those at the temporary microsystem of writing retreats, influence writing. This analysis reveals complex relationships between individuals and social agreements. This interplay of beliefs and structures in the development of writing practices is observable in Jane's narrative:

\footnotetext{
'Time and energy are not infinite, so those who do not expect [relational aspects of work] of themselves have more time and energy freed up for other aspects of the job, including writing for publication.... On the other hand, while these relational aspects of the job may be taking time, the relational aspects of the job can indeed be energising' (Jane 163-166).
}

This suggests differing process beliefs regarding academic work, and perceived gendered process beliefs, where two models meet. It might be that the macrosystem influenced her process beliefs, her idea of what is required to do academic work. Jane referred to this as the 'labour of care', which she explained as relating to the affective, relational aspects of academia, such as supporting distressed students. This relational aspect, while often remaining invisible, requires energy and time, which increases the workload and makes it more difficult to prioritise writing. She believed that this should be made more visible, as those 'who are privileged by the current hierarchies associated with care will continue to have that privilege reinforced' (189-191). While she agreed that this is frequently, but not exclusively, gendered (i.e. related to the macrosystem), she suggested that those who do not provide care will find it easier to prioritise writing within their workload. Writing retreats provide a way to make these caring roles visible 
by providing opportunities to be absent from caring roles (at home or at work). Jane therefore had process belief that the macrosystem could be altered by means of writing retreats, i.e. increasing the visibility of care.

Apart from one who was in a managerial position, all participants discussed the context and systems they worked in rather than their individual beliefs about their ability to achieve research output. Structured Writing Retreats do not resolve ambivalence about meritocracy across the Higher Education sector. They do enable women to increase their research output and possibly the quality of output, but there is a perception of 'moving goalposts' in the application of criteria for career progression - a lack of meritocracy and a continuing gender gap in managerial and professorial posts, and the gender pay gap persists. This gendered analysis may explain why women get so much out of retreats.

While these retreats were not intended to be women-only, they appeared to help women who attended to form beliefs and perform processes that enabled them to achieve their writing goals. While these participants did not provide specifically gendered accounts of their experiences, and while we do not know if analyses of men's or other women's experiences would produce the same results, we know that the systems they are talking about, the systems in which they work, are gendered (David 2015, HEFCE 2011, HESA 2017a \& b). This study sheds light on how they understand and navigate these environments.

\section{Limitations}


Synchronous online chat was chosen for its convenience, availability and versatility, but it led to some problems. Two participants forgot about the planned interview. It was time-consuming for the interviewer, when there were unexplained pauses in questionand-answer. The interviewer did not know whether participants at the other end of the line were doing other tasks or thinking about their answers. The interviewer expected online discussion to have the same immediacy as online chat with friends on Whatsapp or Messenger, but the response rate was slow. While it generated interesting data, it did not appeal to this interviewer as an effective tool, unless participants were able to respond quickly.

In addition, the number of participants is a limitation, and because more women declined than accepted to be interviewed, there may be a selection effect in this sample. Most of the participants in this study continued to attend writing retreats, which may also reflect a process of self-selection for this study.

\section{Conclusion}

This research explored the questions of why writing retreats are attractive to women than men and why women seem to benefit from them. We used a transactional approach to identify participants’ perceptions, in order to answer the first question, and a systems approach, to answer the second.

Six women who had attended Structured Writing Retreats identified factors that they felt inhibit their careers: 'moving goalposts' and ambivalence about the concept of ‘career’ when goalposts are moving and lack of control over systemic and structural forces. One interpretation is that writing retreats create a space where it is possible to 
limit the impact of these factors on women's writing and related scholarly processes, and where they can achieve productivity and other benefits important for their careers. Our analysis shows that a Structured Writing Retreat is one space where women can develop process, performance, prospect and profit beliefs in relation to their writing. It suggests that by creating this microsystem women can sustain beliefs that are key for academic writing (2016). Whether this works for all women, and/or for men as well as women, we do not know, and these are questions for further research. Interestingly, family-related matters did not seem to be the barriers for these participants that they could have been (Richard et al. 2015),

However, ambivalence in responses - particularly in relation to research assessment, management and overload - is a reminder of the overarching, potentially destructive, systems in which these women work, where equality is still a 'distant prospect' (David 2015, 24, Stengers and Despret 2014). This is not to say that women academics do not have the capacity to overcome barriers to career progression, but that systemic discriminatory practices may prevent them from invoking their capacity. This research shows that some women can counter some of these discriminatory practices, some of the time, at writing retreats.

Therefore, what we conclude is that our analysis of these women's experiences suggests that the benefits of writing retreats are circumscribed: although some women may be enabled, to some extent, to progress in academic careers through experience of the microsystems of writing retreats, these retreats do not address the systemic problem. In fact, the women in this study are aware of the limitations of writing retreats in this 
regard. In fact, it could be that this awareness is a factor in what seems to be a problem with sustaining beliefs associated with productive writing.

Why do women attend writing retreats? These retreats can provide a space where women can produce the types of work needed for career progression, rather than waiting for structural and systemic inequality to end. Further research could (as one of the peer reviewers suggested) compare experiences and perceptions of those who had not attended writing retreats, or do before-and-after retreat comparison.

Finally, in a world where work creates risks to a woman's career, health and personal life, we need an intervention that will not only enable writing but also develop self-care (Ball and Olmedo 2013), and writing retreats can provide a space for women to do selfcare work. This study raises inevitable questions about how institutions can do this type of work, perhaps using this and other interventions, to support academic women's careers and lives.

\section{Disclosure statement}

No potential conflict of interest was reported by the authors.

This study was supported by seed corn funding from the Centre for Research in Education at the University of the West of Scotland.

\section{References}

Aiston, S. J. 2015a. "Whose Academy? Gender and Higher Education.” In Investigating Higher Education: A Critical Review of Research Contributions, edited by J. Case, and J. Huisman, 80-96. London: Routledge-Society for Research into Higher Education. 
Aiston, S. J. 2015b. "Women Academics and Research Productivity: An International Comparison.” Gender and Education 27 (3): 205-220.

Ball, S., and A. Olmedo. 2013. "Care of the Self, Resistance and Subjectivity under Neoliberal Governmentalities.” Critical Studies in Education 54(1): 85-96.

Bronfenbrenner, U. 1979. The Ecology and Human Development. Cambridge, MA: Harvard University Press.

David, M. 2015. “Women and gender equality in Higher Education?” Education Sciences 5: 10-25.

Equality Challenge Unit. 2017. A Gap in Our Progress on Gender Equality. Ecu.ac.uk, accessed 10.3.17.

Gale, N.K., Heath, G., Cameron, E., Rashid, S. \& Redwood, S. 2013. Using the framework method for the analysis of qualitative data in multi-disciplinary health research. BMC Medical Research Methodology 13: 117-124.

Gatrell, C., C. L. Cooper, and E. E. Kossek. 2017. “Maternal Bodies as Taboo at Work: New Perspectives on the Marginalizing of Senior Women in Organizations.” Academy of Management Perspectives 31 (3): 239-252. 
Gill, R. 2009. “Breaking the Silence: The Hidden Injuries of Neo-liberal Academia.” In Secrecy and Silence in the Research Process: Feminist Reflections, edited by R. Flood, and R. Gill, 228-244. London: Routledge.

Higher Education Funding Council for England. 2011. Analysis of Data from the Pilot Exercise to Develop Bibliometric Indicators for the REF: The Effect of Using Normalised Citation Scores for Particular Staff Characteristics. London: HEFCE.

Higher Education Statistics Agency. 2017a. Staff at Higher Education Providers in the United Kingdom 2015/2016. hesa.ac.uk, accessed 1.3.17.

Higher Education Statistics Agency. 2017b. Table 2: Academic Staff 2015/2016. Hesa.ac.uk, accessed 7.11.17.

Kempenaar, L., and R. Murray. 2016. "Writing by Academics: A Transactional Systems Model for Academic Writing Behaviours.” Higher Education Research and Development 35 (5): 940-950.

Kempenaar, L., and R. Murray. 2017. “Writing Programmes for Academics: Application of a Transactional and Systems Analysis.” Studies in Higher Education DOI 10/1080/03075079.2017.1329817. 
Kempenaar, L., and R. Murray. 2018. "Widening access to writing support: Beliefs about the writing process are key.” Journal of Further and Higher Education. DOI 10.1080/0309877X.2018.1450964.

Larivière, V., E. Vignola-Gagne, C. Villeneuve, P. Gelinas, and Y. Gingras. 2011. "Sex Differences in Research Funding, Productivity and Impact: An Analysis of Quebec University Professors.” Scientometrics 87 (3): 483-98.

Littler, J. 2013. “Meritocracy as plutocracy? The marketising of ‘equality’ within neoliberalism.” New Formations 80-81: 52-72.

MacLeod, I., L. Steckley, and R. Murray. 2012. “Time is not Enough: Promoting Strategic Engagement with Academic Writing.” Studies in Higher Education 37 (6): 641-54.

Moore, S., M. Murphy and R. Murray. 2010. “Increasing Academic Output and Supporting Equality of Career Opportunity in Universities: Can Writers’ Retreats Play a Role?” Journal of Faculty Development 24(3): 21-30.

Morley, L. 2013. Women and Higher Education Leadership: Absences and Aspirations. London: Leadership Foundation for Higher Education.

Murray, R. 2012. “Developing a Community of Research Practice.” British Educational Research Journal 38 (5): 765- 81. 
Murray, R. 2013. “It’s not a Hobby: Reconceptualizing the Place of Writing in Academic Work.” Higher Education 66 (1): 79-91.

Murray, R. 2014. “Doctoral Students Create New Spaces to Write.” In Writing Groups for Doctoral Education and Beyond: Innovations in Theory and Practice, edited by C. Aitchison, and C. Guerin, 94-109. London: Routledge.

Murray, R. 2015. Writing in Social Spaces: A Social Processes Approach to Academic Writing. London: Routledge-Society for Research into Higher Education.

Murray, R., and Newton, M. 2009. "Writing retreat as structured intervention: Margin or mainstream?” Higher Education Research and Development 28(5): 541-553.

Nielsen, M.W. 2015. "Limits to meritocracy? Gender in academic recruitment and promotion processes.” Science and Public Policy p.scv: 052.

Richard, J. E., G. Plimmer, K-S. Fam, and C. Campbell. 2015. "Publishing Success of Marketing Academics: Antecedents and Outcomes.” European Journal of Marketing 49 (1/2): 123-145.

Savigny, H. 2014. "Women, Know Your Limits: Cultural Sexism in Academia.” Gender and Education 26 (7): 794-809. 
Sonnad, S. S. 2011. “A Writing Group for Female Assistant Professors.” Journal of the National Medical Association 103 (9 \& 10): 811-15.

Stengers, I., V. Despret, and Collective. 2014. Women Who Make a Fuss: The Unfaithful Daughters of Virginia Woolf. Minneapolis, MN: Univocal.

Valentine, G. 1998. "Sticks and stones may break my bones: A personal geography of harassment.” Antipode 30 (4): 305-332. 